City University of New York (CUNY) CUNY Academic Works

2022

\title{
The Translanguaging Pedagogies Continuum
}

Marcela Ossa Parra

CUNY Queens College

Patrick Proctor

Boston College

\section{How does access to this work benefit you? Let us know!}

More information about this work at: https://academicworks.cuny.edu/qc_pubs/521

Discover additional works at: https://academicworks.cuny.edu

This work is made publicly available by the City University of New York (CUNY).

Contact: AcademicWorks@cuny.edu 


\title{
The Translanguaging Pedagogies Continuum ${ }^{1}$
}

\author{
Marcela Ossa Parra² and Patrick Proctor ${ }^{3}$
}

\begin{abstract}
Translanguaging pedagogy is an approach to educational equity that harnesses multilingual learners' communicative repertoires (e.g., home languages, non-standard varieties, gestures) by strategically incorporating them in the classroom to ensure students' active participation and meaningful learning. This paper proposes a research-informed continuum that captures a range of possibilities for integrating translanguaging in language and literacy instruction. This continuum provides insight into how educators may make socially just instructional and curricular decisions that are based on recognizing multilingual students' languages, cultures, and ways of knowing as valuable assets in the classroom.
\end{abstract}

\section{Keywords}

Language, social justice, teaching, literacy, equity

Effective educational approaches that center multilingual learners' lived experiences and linguistic practices are a high-priority issue in the United States and other countries, with intersections between policy and practice. To identify "what works" for supporting multilingual students in schools, federally-funded educational research in this century has tended to target experimental and quasi-experimental research focused on primarily English-only instructional settings (Proctor \& Chang-Bacon, 2020). Recommendations derived from this body of research revolve around ensuring that students designated as "English learners" have exposure and opportunities to use language in both spoken and written forms. However, these

\footnotetext{
${ }^{1}$ Published in Journal of Education, DOI: 10.1177/00220574211053587, journals.sagepub.com/home/jex

${ }^{2}$ Queens College, Flushing, NY, USA

${ }^{3}$ Boston College, Chestnut Hill, MA, USA

Corresponding author:

Marcela Ossa Parra Queens College, School of Education 65 - 30 Kissena Blvd., Flushing, NY, 11367, USA

Email: mossaparra@qc.cuny.edu
} 
recommendations typically fail to provide guidance on how to move instruction beyond English monolingual approaches.

Students labeled as "English learners" in the U.S. are, in fact, multilingual; that is, they navigate at least two languages on a daily basis (García \& Li, 2014). While we know that multilingual students benefit from accessing all of their languages in instructional contexts (García \& Kleifgen, 2018), unfortunately, the language of instruction in the U.S. and other countries is primarily monolingual and delivered in the dominant societal language (i.e., English in the U.S). This systemic monolingualism requires that multilingual students accommodate an educational system that should be working to engage students around their linguistic strengths.

An alternative to this stubborn monolingualism is translanguaging pedagogy. Translanguaging pedagogy encompasses classroom language practices and instructional strategies that recognize and strategically integrate multilingual students' communicative repertoires (e.g., home languages, non-standard varieties, gestures) to ensure their active participation and meaningful learning. A communicative repertoire comprises the diverse linguistic, communicative, and semiotic resources people draw from in their communication and meaning-making (Blommaert, 2010). By stimulating students to draw from their entire communicative repertoire, translanguaging pedagogy opens and expands opportunities for engagement in meaningful language and literacy practices, thus ensuring more equitable learning environments.

Essentially, educators should seek to tap the translanguaging corriente in their work with multilingual learners. Corriente is Spanish for 'current,' precisely as related to the flow of a river. A river's corriente may appear to be flowing uniformly or not moving at all when viewed from above, but the corriente becomes evident when experienced from within. Thus, the 
translanguaging corriente serves as a metaphor for multilingual students' language practices in the classroom (García et al., 2017). It captures the underlying fluidity, resistance, and creativity in students' language practices as they draw from their full communicative repertoires to negotiate meaning and express understanding.

In describing how to harness the corriente for instructional practice, we draw from current research and propose a translanguaging continuum. This continuum captures a range of possibilities for dismantling monolingual ideologies and ensuring fair learning conditions for multilingual students. We propose three discrete points on the translanguaging continuum: On one end, there is "listening" to the corriente in which teachers recognize students' naturallyoccurring language practices; in the middle is "channeling," in which teachers accept and promote flexible language use in their classrooms; on the far end is "flowing" with the corriente, in which teachers explicitly plan and implement translanguaged instruction.

Additionally, we adopt Fraser's (Fraser \& Honneth, 2003) theory of social justice for explaining how translanguaging pedagogies support equitable learning conditions for multilingual students. This theory approaches social justice from three perspectives -recognition, redistribution, and representation- to ensure fair participation conditions for all social group members (Dahl, Stoltz, \& Willig, 2004). Recognition attributes equal status to all groups by acknowledging their standing as full partners in social interactions. The listening dimension of the continuum focuses on recognition by positioning multilingual students' languages and cultural knowledge as valuable assets in the classroom. Redistribution ensures access to material and symbolic capital. The channeling point in the continuum addresses redistribution by guaranteeing that multilingual students may use their entire linguistic repertoire to participate in the classroom's literacy practices. Finally, representation ensures that the voices and knowledge 
of historically marginalized communities are heard. The flowing dimension centers on representation by deliberately integrating multilingual students' cultural and linguistic funds of knowledge into the curriculum.

One general question about the feasibility of translanguaging pedagogies, particularly in the United States, is whether monolingual teachers, who currently constitute the majority of the teaching force, may implement these pedagogies. Thus, the translanguaging continuum is meant to provide affirmative evidence that there are multiple ways of navigating the translanguaging corriente for all teachers. Furthermore, this continuum seeks to stimulate reflection on whether and how instructional and curricular decisions guarantee equitable learning conditions for multilingual students.

In the sections that follow, we discuss the purposes of translanguaging pedagogy followed by Fraser's (Fraser \& Honneth, 2003) theory of social justice. We then characterize the three points on the translanguaging continuum and review extant research relative to each point, proposing instructional and social justice implications derived from this research.

\section{Translanguaging Pedagogy}

Cen Williams introduced translanguaging pedagogy in Welsh bilingual education programs to bilingually deliver instruction (Lewis et al., 2012). Ofelia García (2009) expanded the scope of translanguaging pedagogy by giving it a critical and transformative turn and also adopted this concept to characterize multilingual language practices outside the classroom (Lewis et al., 2012). Translanguaging pedagogy is better characterized as a plural range of pedagogies, all sharing an interest in challenging monolingual instruction and promoting social justice (García \& Leiva, 2014; Poza, 2017). 
Traditionally, the media of instruction in bilingual and language education programs have been defined based on monolingual ideologies (García, 2009; Palmer et al., 2014). Bilingual programs establish language separation policies that ensure that each language is addressed separately. Similarly, language programs (e.g., foreign language, English as a second language, heritage language) have traditionally forbidden using any language other than the target language to ensure exposure and practice in the target language. Immersion in the societal language is also promoted in contexts where the medium of instruction is different from the child's home language, such as in immigrant-receiving countries like the United States or multilingual countries like South Africa. These language separation policies impose arbitrary boundaries that limit multilingual students' ability to use their linguistic repertoire fluidly.

By contrast, translanguaging pedagogies seek to disrupt these strict linguistic separations by arguing that multilingual people do not operate in linguistic isolation. In this sense, these pedagogical approaches propose permeable language boundaries that stimulate students to use all of. their communicative resources to participate in the classroom. Furthermore, translanguaging pedagogies are founded in the recognition of students' and their communities' language practices, and thus their funds of knowledge (Moll et al., 1992). As Banda (2018) establishes, "translanguaging is not merely about language mixing and using of bit-and-pieces of language, it is also about infusing local knowledge systems and cultures in pursuit of excellence in teaching and learning in multilingual contexts" (p. 211). In this sense, translanguaging pedagogies promote meaningful and transformative literacy practices that recognize and integrate multilingual students' cultural and linguistic knowledge.

\section{Social Justice}


The translanguaging continuum is a tool for reflecting on instructional and curricular decisions that guarantee that all students may equitably participate in the classroom's literacy practices. This aligns with Fraser's ( Fraser \& Honneth, 2003) focus on "participatory parity," which refers to social arrangements that give all social group members the status and conditions to interact on fair terms. Fraser proposes three dimensions -recognition, redistribution, and representation- for understanding the social justice conditions in particular institutions.

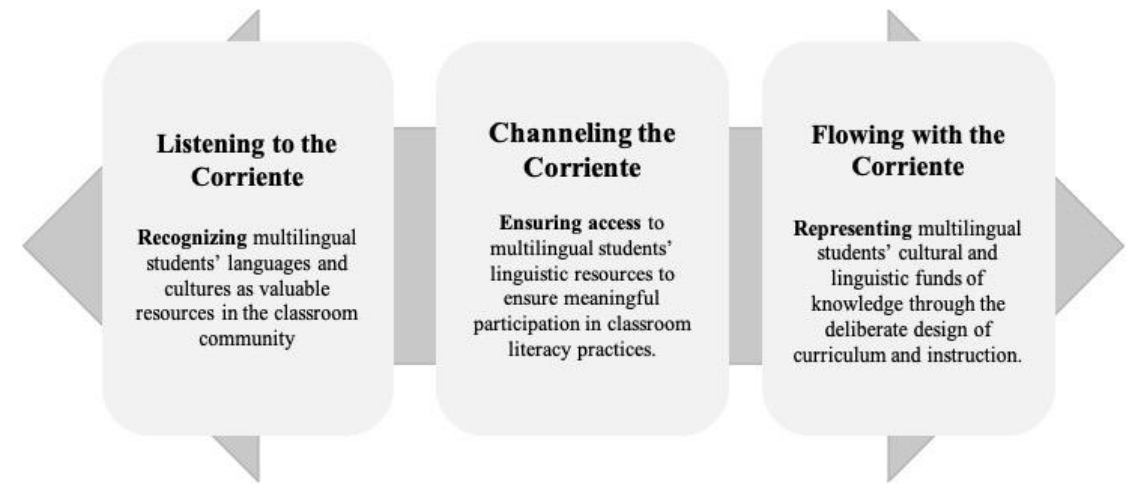

Figure 1. The translanguaging pedagogies continuum with connections to Fraser's social justice framework in bold

Recognition entails acknowledging diverse identities and cultures to ensure that everyone has equal standing as full partners in the social interactions institutionalized within a particular society. Recognition has been the focus of the social justice claims in translanguaging theory by denouncing the workings of prevalent monolingual ideologies in erasing multilingual communities' language practices and thus their voices and status as equal partners in institutionalized social processes such as schooling.

Redistribution focuses on the access different groups have to material and symbolic capital, such as the knowledge and skills needed to flourish in a particular society. Schools are vital institutions in providing access to symbolic capital by imparting rigorous instruction focused on developing higher-order skills (Lingard \& Keddie, 2013). However, too often, 
multilingual students face language barriers that prevent their access to curricula and rigorous education while developing proficiency in the majoritized language of schooling.

Finally, representation addresses questions around whose voices, experiences, and perspectives are considered when designing policies, institutions, and social arrangements (Dahl, Stoltz, \& Willig, 2004). In education, issues of representation raise questions about whose knowledge is included in the curriculum. Representation in the curriculum is necessary for students to see that the knowledge and accomplishments of their communities are worthy and that they will also be able to influence their social milieu. By seeing themselves in the curriculum (e.g., learning about issues that help students to critically consider their lives and their role in the world), students develop an understanding of individual and collective agency that "nurtures active citizenship" (Lingard \& Keddie, 2013).

\section{Translanguaging Pedagogies Continuum}

The translanguaging pedagogies continuum (see Figure 1) highlights the degrees to which teachers can engage the translanguaging corriente in their classrooms. As indicated, this continuum proposes a range that spans from recognizing students' language practices to fully and deliberately designing translanguaged instruction. No teacher ever consistently resides at a single point on the continuum as lessons, content, and language proficiencies all impact where instruction may reside. Further, the proposed dimensions are neither mutually exclusive nor exhaustive. Instead, they serve as a starting point for teachers to expand their knowledge of their students' language and literacy practices and the possibilities for integrating them into their instructional practice.

\section{Listening to the corriente}


Listening to the corriente addresses the recognition dimension of social justice by building knowledge about multilingual students' language practices. This knowledge supports the development of interpretive frameworks that recognize multilingualism as an asset in the classroom community. In this sense, listening to the corriente entails learning about our students and identifying the resources they bring into the classroom.

Research on listening to the corriente. Studies in early childhood classrooms show that young children engage in translanguaging to discuss texts during group work (Link, 2011; Soltero-Gonzalez, 2009). They also fluidly use their languages to support each other in understanding texts by translating unknown words or paraphrasing challenging ideas in their stronger language (Link, 2011). Research on writing has shown that some elementary students also use translanguaging as a self-regulation mechanism through which they plan, problemsolve, and develop textual voices that convey their bilingual identities (e.g., strategically integrate words/phrases from their languages in their final products) (Cenoz \& Gorter, 2011; Velasco \& García, 2014).

Unfortunately, it is possible (if not likely) that as students are socialized in monolingual classroom language practices, they purposefully refrain from translanguaging practices in these contexts. For example, Jonsson (2013) reported that her adolescent multilingual participants from a Swedish international boarding school used their languages and literacy repertoires in complex ways in their everyday life. However, they avoided translanguaging in more formal situations, such as school, since they perceived this was not a sanctioned practice. Similarly, Daniel (2018) reported that, while recently arrived multilingual middle school immigrants strategically integrated their languages and used multiple modalities when doing their homework 
in an afterschool program, they did not draw from these diverse resources in their regular classrooms.

Research on multilingual students' language practices shows how they forge their own "linguistic third spaces" (Flores \& García, 2011; Hornberger, 2005) by combining official and unofficial language practices as they engage in school-based literacy practices. However, monolingual language policies in the classroom may serve as a barrier to forming these spaces, which should raise awareness of the relevance of listening to the corriente as a valuable resource in the classroom community.

Instructional and social justice implications. Listening to the corriente supports a strengths-based stance founded on the belief that students contribute rich cultural and linguistic knowledge to classroom literacy practices. Teaching for social justice requires us to become aware of the interpretive frameworks that inform our understandings of multilingual learners and revise these frameworks as we engage in inquiry about our practice (Cochran-Smith, 2010). These frameworks are "the filters through which teachers make decisions, form relationships, and support learning... [these] are powerful mediators of practice and thus of students' opportunities and experiences" (Cochran-Smith, 2010, p. 436). Listening to the corriente calls for challenging monolingual ideologies that have traditionally shaped the teaching and learning process.

Educators can start listening by recognizing and learning about the communicative resources (e.g., gestures, actions, images) that multilingual students use when participating in classroom and out-of-school literacy practices. In this sense, to recognize the corriente, it is necessary to listen, observe, and document how multilingual students use their communicative resources when they read, interpret, and produce texts. It is also relevant to invite students into a 
conversation about how they use their communicative resources in their literacy practices. These conversations will deepen teachers' knowledge about and validate their multilingual students' language and literacy practices. By showing interest in learning more about how students use these resources, teachers will send the message that these practices are relevant and worthwhile.

\section{Channeling the Corriente}

When channeling the corriente, teachers actively foster translanguaging practices to ensure that their multilingual students meet content and language curricular expectations. Channeling the corriente addresses the redistribution dimension of social justice by guaranteeing that multilingual students have access to the same rigorous curriculum as the students already proficient in the majoritized language of instruction. By channeling the corriente, also teachers engage multilingual students in cognitively challenging activities even if they are not yet proficient in the language of instruction. By encouraging multilingual students to use their full linguistic repertoires, teachers provide supports to access the curriculum, rather than changing the curriculum for one group of students versus another.

Research on channeling the corriente. Ethnographic studies in bilingual programs have shown that, despite strict school policies that mandate the use of only one language in the classroom, teachers are adept at channeling the corriente in their classrooms (Durán \& Palmer, 2014; Creese \& Blackledge, 2010). Teachers facilitate these flexible discourse practices by accepting students' contributions in any language, including their vernaculars (Durán \& Palmer, 2014; Gort \& Sembiante, 2015; Sayer, 2013). Although teachers typically use the allocated language of instruction, there are also instances in which they use the other language. Teachers' strategically use their languages to achieve pedagogical purposes such as scaffolding and differentiating instruction for students (Durán \& Palmer, 2014; Gort \& Sembiante, 2015); checking or reinforcing understanding (Creese \& Blackledge, 2010); and modeling 
translanguaging practices for their students (Durán \& Palmer, 20145). This strategic language use differs from instructional replication in other languages since it adapts instruction to ensure access and participation.

Research in multilingual classrooms where instruction is imparted monolingually shows that teachers stimulate translanguaging practices in different ways. For example, teachers encourage students to use their preferred language to share their understandings (Brisk \& Ossa Parra, 2018). Other studies have shown that teachers invite multilingual students to share their knowledge of their different languages (e.g., provide labels for vocabulary words, identify cognates) (Bonacina-Pugh, 2013; Durán \& Palmer, 2014). Teachers also channel the corriente by strategically grouping students according to their linguistic skills to, for example, discuss content or help each other proofread texts (Banda, 2018; Bauer, Presiado, \& Colomer, 2017; Martín Beltrán, 2014).

By having access to their meaning-making tools (e.g., languages, gestures) and their prior knowledge, students have more opportunities for building and displaying their understandings (Banda, 2018; Gort \& Sembiante, 2015; Hopewell, 2011; Sayer, 2013) and engaging with complex topics and higher-order skills (Hamman, 2018; Palmer et al., 2014). Additionally, translanguaging practices support language learning since students may establish connections between their new language and their other language(s). For example, students may connect meanings for concepts they already know with labels in the new language (Gort \& Sembiante, 2015; Hamman, 2018). They may also identify patterns across languages, analyze syntax, and share linguistic insights (Hamman, 2018; Hopewell, 2011; Martín-Beltrán, 2014).

Instructional and social justice implications. In channeling the corriente, teachers enact their belief in the value of integrating multilingual students' linguistic resources into the 
classroom's literacy practices. This integration ensures fairer learning conditions for multilingual students since they have access to all their meaning-making tools and prior knowledge. In this sense, channeling the corriente is a social justice action through which teachers guarantee that their multilingual students have more equitable opportunities to build the knowledge and skills that make part of the curriculum and, in the future, reap the benefits of receiving a high-quality education (e.g., college access, lifelong learning, community engagement).

Channeling the corriente entails designing multilingual learning environments where students are encouraged to use their communicative resources fluidly. This design starts with actions such as including students' languages on classroom walls, gathering books and materials in students' languages, and, when deemed appropriate, inviting students to share labels in their languages for key terms during mini-lessons. These simple actions lay the foundation for channeling by sending the message to students that their languages are welcomed and encouraged when engaging in classroom literacy practices.

Encouraging students to engage in translanguaging may seem counterproductive if teachers don't speak their students' home languages. As such, teachers who channel the corriente often seek support from community members (e.g., relatives, older students, paraprofessionals, student teachers). In the community, it is possible to find people who serve as interpreters and cultural and linguistic knowledge brokers who can help make the content accessible in students' languages (Brisk \& Ossa Parra, 2018). Additionally, technological resources such as online translators are helpful tools for channeling the corriente and supporting multilingual students' meaningful participation in the classroom's literacy practices. In this sense, channeling the corriente entails building relationships with the community and seeking various supports to help students meaningfully engage with the curriculum. 
Strategic grouping is another approach to channeling the corriente reported in the research (Banda, 2018; Bauer, Presiado, \& Colomer, 2017; Martín Beltrán, 2014). For instance, grouping students according to their home languages opens up spaces for them to use their linguistic resources fluidly while engaged in literacy practices such as discussing, brainstorming, doing research, and drafting. After this, students can work together to translate their work and present their conclusions in the medium of instruction. Heterogeneous groupings where students with different proficiency levels in the language of instruction are also beneficial for students to share their linguistic expertise. In these groups, multilingual students have the opportunity to share their linguistic knowledge with their peers and get support in proofreading their work. In addition to strategically grouping students, it is also necessary to teach students how to work in these groups effectively. This entails having them reflect on the meaning of collaborating with

others and providing clear expectations about their participation in these groups, such as listening actively to peers, building on their contributions, providing constructive feedback, and staying focused on the work.

\section{Flowing with the Corriente}

Flowing with the corriente reflects a commitment to the deliberate design of curriculum and instruction that includes multilingual students' cultural and linguistic funds of knowledge (Flores \& García, 2018). It implies questioning whether students' languages, experiences, and ways of knowing are represented and engaged as worthy and relevant areas of study in the official curriculum. In this sense, flowing addresses the representation dimension of social justice by opening up spaces in the curriculum where multilingual students' voices, experiences, and realities are centered. This representation enables multilingual students to see themselves and 
their communities reflected in the curriculum and envision diverse possibilities to participate in society.

When teachers flow with the corriente, they design translanguaging spaces where the boundaries separating language and literacy practices into categories such as literary-vernacular, academic-everyday, or target-home language become permeable (Li, 2018). This permeability opens possibilities for understanding how language works and critically examining its role in maintaining or changing power relationships. The notion of a translanguaging space can be traced back to Bhabha's (Rutherford, 1990) concept of hybridity as a "third space" where new ways of being and knowing emerge. By flowing with the corriente in the curriculum, teachers design a democratic and inclusive space where students can experiment with language, bring their diverse sources of knowledge into the classroom, and develop their confidence and agency as active participants in the classroom community.

Research on flowing with the corriente. The research informing flowing encompasses studies on instructional designs that integrate multilingual students' linguistic and cultural funds of knowledge. These designs build on students' knowledge to deepen their understanding and critical awareness of how language and texts work and include intervention studies examining the relationship between translation and reading comprehension and illustrative case studies that demonstrate the potential of translanguaged designs for critical literacy instruction.

Several intervention studies have explored the role of the strategic use of translation as a pedagogical tool supporting students' more profound engagement with texts and language (Borrero, 2011; David et al., 2019; Jiménez et al., 2015). These interventions harnessed multilingual students' natural ability to move between their languages in their instructional designs. For example, in the "Young Interpreters Program," $7^{\text {th }}$ and $8^{\text {th }}$ graders were prepared to 
serve as interpreters in their school by teaching them translation skills, such as paraphrasing oral and written texts (Borrero, 2011). TRANSLATE (Teaching reading and new strategic language approaches to English learners) is another example of an intervention study in which middle school students were engaged in close reading by translating the texts passages from English to Spanish (Jiménez et al., 2015). Research on these instructional designs suggests that having students translate select text excerpts or learn the necessary skills to serve as interpreters in their schools enhances their reading comprehension skills and increases their awareness of the value of their multilingual skills (Borrero, 2011; Jiménez et al. 2015).

A set of illustrative case studies also portray how, through translanguaging pedagogy, students are socialized in academic discourses and literacy by reading different types of texts, fluidly using their languages, and bridging home and academic knowledge. (Flores \& García, 2014; Stewart \& Hansen-Thomas, 2016; authors). These case studies illustrate the potential of translanguaging pedagogy to promote critical literacy practices in which historically silenced voices are brought into the classroom to stimulate students' reflection about their identity, and challenge power structures that perpetuate inequality.

Instructional and social justice implications. Flowing with the corriente entails designing literacy instruction where multilingual students use their linguistic and cultural funds of knowledge. In these designs, teachers open new spaces where multilingual students see their languages and cultures represented in the classroom's literacy practices. For example, teachers may validate and further develop these skills by providing instruction on translation as a paraphrasing activity to deliver a clear message that conveys the original idea. The research described above suggests that integrating students' multilingual skills supports literacy objectives and the sense of worth that students have in their multilingualism. 
Teachers may also flow with the corriente by encouraging their students to use their entire linguistic repertoire to discuss bilingual stories in which authors use translanguaging in their writing. In these discussions, students have the opportunity to critically analyze the author's language choices by considering elements related to culture and audience and stimulate reflection about the author's and the students' own bilingual identities (García et al., 2017). Teachers may also integrate multiple modes of representation, including non-traditional texts, song lyrics, for example, that expand notions of literacy and classroom language to promote critical conversations about issues related to students' lived experiences broadly (Flores \& García, 2014; Stewart \& Hansen-Thomas, 2016; Ossa Parra \& Proctor, 2021). These multiple modes of representation open up translanguaging spaces where the meaning of academic discourses and literacy is expanded to include students' knowledge and experiences. Students engage in scholarly work focused on their communities and their role in broader historical and socio-political processes in these spaces how these translanguaging spaces look like in the classroom (to learn more about how these translanguaging spaces see, for example, CUNY NYSIEB, 2020; España \& Herrera, 2020; Espinoza \& Ascenzi-Moreno, 2021; García et al., 2017)

\section{Conclusion}

We offer the translanguaging continuum as a research-grounded metaphor for reflecting on how the translanguaging corriente can be seen and navigated in classrooms serving multilingual students to ensure their participation as equal partners in classroom literacy practices. The translanguaging continuum provides insight into how educators may make socially just instructional and curricular decisions that are based on the recognition, access, and representation of multilingual students' languages, cultures, and ways of knowing. As we have 
already noted, the three dimensions on the continuum are not mutually exclusive. Instruction with multilingual learners can reside at any point in the continuum for any given day or lesson. Approaching instruction with the continuum in mind will go a long way toward providing a more socially just educational experience for multilingual students.

\section{References}

Banda, F. (2018). Translanguaging and English-African mother tongues as linguistic dispensation in teaching and learning in a black township in Cape Town. Current Issues in Language Planning, 19(2), 198-217. https://doi.org/10.1080/14664208.2017.1353333

Bauer, E.B., Presiado, V., \& Colomer, S. (2017). Writing through partnership: Fostering translanguaging in children who are emergent bilinguals. Journal of Literacy Research, 49(1), 10 - 37. https://doi.org/10.1177/1086296X16683417

Blommaert, J. (2010). The Sociolinguistics of Globalization. Cambridge University Press.

Bonacina-Pugh, F. (2013). Multilingual label quests: A practice for the 'asymmetrical' multilingual classroom. Linguistics and Education, 24, 142 - 164. https://doi.org/10.1016/j.linged.2012.12.006

Borrero, N. (2011). Nurturing students' strengths: The impact of a school-based students interpreter program on Latino/a students' reading comprehension and English language development. Urban Education, 46(4), 663 - 688.

https://doi.org/10.1177/0042085911400333

Brisk, M.E., \& Ossa Parra, M. (2018). Mainstream classrooms as engaging spaces for emergent bilinguals: SFL theory, catalyst for change. In Ruth Harman (Ed.), Bilingual Learners 
and Social Equity. Critical Approaches to Systemic Functional Linguistics (pp. 127-151). Springer.

Cenoz, J. \& Gorter, D. (2011). Focus on multilingualism: A study of trilingual writing. The Modern Language Journal, 95(3), 356 - 369. https://doi.org/10.1111/j.1540-4781.2011.01206.x

Cochran-Smith, M. (2010). Toward a theory of teacher education for social justice. In M. Fullan, A. Hargreaves, D. Hopkins \& A. Lieberman (Eds.) The International Handbook of Educational Change (2 ${ }^{\text {nd }}$ Ed, pp. 445 - 467). Springer.

Creese, A. \& Blackledge, A. (2010). Translanguaging in the bilingual classroom: A pedagogy for teaching and learning. The Modern Language Journal, 94(i), 103 - 115. https://doi.org/10.1111/j.1540-4781.2009.00986.x

CUNY-NYSIEB (2020). Translanguaging and transformative learning for emergent bilingual students. Lessons from the CUNY-NYSIEB Project. Routledge.

Dahl, H.M., Stoltz, P., \& Willig, R. (2004). Recognition, redistribution, and representation in a capitalist global society: An interview with Nancy Fraser. Acta Sociologica, 47(4) $374-$ 382. https://doi.org/10.1177/0001699304048671

Daniel, S.M. (2018). Resettled refuge youth leveraging their out-of-school literacy practices to accomplish schoolwork. Mind, Culture, and Activity, 25(3), 263 - 277. https://doi.org/10.1080/10749039.2018.1481092

Duran, L. \& Palmer, D. (2014). Pluralist discourses of bilingualism and translanguaging talk in classrooms. Journal of Early Childhood Literacy, 14(3), 367 - 388. https://doi.org/10.1177/1468798413497386

España, C. \& Herrera, L.Y. En comunidad. Lessons for centering the voices and experiences of bilingual Latinx students. Heinemann. 
Espinosa, C.M. \& Ascenzi-Moreno, L. (2021). Rooted in Strength. Using Translanguaging to Grow Multilingual Readers and Writers. Scholastic.

Flores, N. \& García, O. (2014). Linguistic third spaces in education: teacher's translanguaging across the bilingual curriculum. In D. Little, C. Leung, \& P. Van Avermaet (Eds). Managing Diversity in Education: Language, policies, pedagogies. Multilingual Matters. (pp. $243-256)$.

Fraser, N. \& Honneth, A. (2003). Redistribution or Recognition? A Political-Philosophical Exchange. Verso.

García, O. (2009). Bilingual education in the $21{ }^{\text {st }}$ Century. A Global Perspective. WilleyBlackwell.

García, O., Ibarra Johnson, S. \& Seltzer, K. (2017). The Translanguaging Classroom: Leveraging Bilingualism for Learning. Caslon Publishing.

García, O., \& Kleifgen, J. A. (2018). Educating emergent bilinguals: Policies, programs, and practices for English language learners (2nd ed.). Teachers College Press.

García, O. \& Leiva, C. (2014). Theorizing and Enacting Translanguaging for Social Justice. In A. Blaledge \& A. Creese (Eds). Heteroglossia As Practice and Pedagogy. Springer. (pp. $199-216)$.

García, O. \& Li, W. (2014). Translanguaging. Language, Bilingualism and Education. Palgrave Macmillan

Gort, M. \& Sembiante, S.F. (2015). Navigating hybridized language learning spaces through translanguaging pedagogy: Dual language preschool teachers' languaging practices in support of emergent bilingual children's performance of academic discourse. International Multilingual Research Journal, 9(1), 7 - 25. https://doi.org/10.1080/19313152.2014.981775 
Hamman, L. (2018). Translanguaging and positioning in two-way dual language classrooms: a case for criticality. Language and Education, 32(1), 21 - 42. https://doi.org/10.1080/09500782.2017.1384006

Hopewell, S. (2011). Leveraging bilingualism to accelerate English reading comprehension. International Journal of Bilingual Education and Bilingualism, 14(5), 603 - 620. https://doi.org/10.1080/13670050.2011.564274

Hornberger, N. (2005). Opening and filling up implementational and ideological spaces in heritage language education. The Modern Language Journal, 89(4), 605-609. http://www.jstor.org/stable/3588632

Jimenez, R.T., David, S., Fagan, K., Risko, V.J, Pacheco, M., Pray, L., \& Gonzales, M. (2015). Using translation to drive conceptual development for students becoming literate in English as an additional language. Research in the Teaching of English, 49, (3), 248 271. http://www.jstor.org/stable/24398702

Jonsson, C. (2013). Translanguaging and multilingual literacies: diary-based case studies of adolescents in an international school. International Journal of the Sociology of Language, (224), 85 - 117. https://doi.org/10.1515/ijsl-2013-0057

Lewis, G., Jones, B. \& Baker, C. (2012). Translanguaging: origins and development from school to street and beyond. Educational Research and Evaluation, 18(7), 641 - 654. https://doi.org/10.1080/13803611.2012.718488

Li, W. (2018). Translanguaging as a practical theory of language. Applied Linguistics, 39(1), 9 30. https://doi.org/10.1093/applin/amx039 
Lingard, B. \& Keddie, A. (2013). Redistribution, recognition, and representation: working against pedagogies of indifference. Pedagogy, Culture, and Society, 21(3), 427 - 447. https://doi.org/10.1080/14681366.2013.809373

Link, H.K. (2011). Hola means hello: The intersection of language ideologies and language policies in a school of the New Latino Diaspora. Working Papers in Educational Linguistics.

Martín-Beltrán, M. (2014). “What do you want to say?” How adolescents use translanguaging to expand learning opportunities. International Multilingual Research Journal, 8, 208 - 230. https://doi.org/10.1080/19313152.2014.914372

Moll, L.C., Amanti, C., Neff, D., \& Gonzalez, N. (1992). Funds of knowledge for teaching: Using a qualitative approach to connect homes and classrooms. Theory Into Practice, 31(2), 132 - 141. https://doi.org/10.1080/19313152.2014.914372

Ossa Parra, M., \& Proctor, C.P. (2021). Translanguaging to understand language. TESOL Quarterly, 55(3), 766-794. https://doi.org/10.1002/tesq.3011

Palmer, D.K., Mateus, S.G., Martínez, R.A., \& Henderson, K. (2014). Reframing the debate on language separation: Toward a vision for translanguaging pedagogies in the duallanguage classroom. The Modern Language Journal, 98(3), 757 - 772. https://doi.org/10.1111/modl.12121

Poza, L. (2017). Translanguaging: Definitions, implications and further needs in burgeoning inquiry. Berkeley Review of Education,6(2), 101 - 128. https://doi.org/10.5070/B86110060 
Proctor, C.P., \& Chang-Bacon, C (2020). Demographic Realities and Methodological Flexibility in Literacy Teaching and Research. In E.B Moje, P Afflerbach, P Enciso, \& H.K Lesaux (Eds.), Handbook of Reading Research (pp. 17-36). Longman.

Rutherford, J. (1990). The Third Space. Interview with Homi Bhabha. In J. Rutherford (Ed). Identity: Community, Culture, Difference. Lawrence \& Wishart. (pp. 207 - 221).

Sayer, P. (2013). Translanguaging, TexMex, and bilingual pedagogy: Emergent bilinguals learning through the vernacular. TESOL Quarterly, 47(1), 63 - 88. https://doi.org/10.1002/tesq.53

Soltero-González, L. (2009). The hybrid literacy practices of young immigrant children: Lessons learned from an English-Only preschool classroom. Bilingual Research Journal, 31, 75 93. https://doi.org/10.1080/15235880802640581

Stewart, M.A. \& Hansen-Thomas, H. (2016). Sanctioning a space for translanguaging in the secondary English classroom: a case of a transnational youth. Research in the Teaching of English, 50(4), $450-472$.

Velasco, P. \& García, O. (2014). Translanguaging and the writing of bilingual learners. Bilingual Research Journal, 37(1), 6 - 23. https://doi.org/10.1080/15235882.2014.893270 
Ossa Parra \& Proctor, 202223 